Article

\title{
Genomic Diversity, Population Structure, and Signature of Selection in Five Chinese Native Sheep Breeds Adapted to Extreme Environments
}

\author{
Adam Abied ${ }^{1,2}{ }^{-}$, Alnoor Bagadi ${ }^{2}$, Farhad Bordbar ${ }^{1}$, Yabin Pu ${ }^{1}$, Serafino M.A. Augustino ${ }^{3}$, \\ Xianglan Xue ${ }^{1}{ }^{\mathbb{D}}$, Feng Xing ${ }^{4}$, Gebremedhin Gebreselassie ${ }^{1} \mathbb{D}$, Jian-Lin Han ${ }^{5,6} \mathbb{D}$, \\ Joram M. Mwacharo ${ }^{7}$, Yuehui Ma ${ }^{1}$ and Qianjun Zhao ${ }^{1, *}$ \\ 1 Institute of Animal Science (IAS), Chinese Academy of Agricultural Sciences (CAAS), Beijing 100193, China; \\ aa.abied89@gmail.com (A.A.); farhadnevergiveup@yahoo.com (F.B.); puyabin@caas.cn (Y.P.); \\ larrykazunari@126.com (X.X.); gerageruggg@gmail.com (G.G.); yuehui.ma@263.net (Y.M.) \\ 2 Dry Land Research Center (DLRC) and Animal Production, Agricultural Research Corporation (ARC), \\ Wad Madani 511, Sudan; alnoorbagadi@gmail.com \\ 3 College of Animal Science and Technology, China Agricultural University (CAU), Beijing 100193, China; \\ serafino156@gmail.com \\ 4 College of Animal Science, Talimu University (TU), Xinjiang, Alar 843300, China; xingfeng2001@126.com \\ 5 CAAS-ILRI Joint Laboratory on Livestock and Forage Genetic Resources, Institute of Animal Science, \\ Chinese Academy of Agricultural Sciences (CAAS), Beijing 100193, China; h.jianlin@cgiar.org \\ 6 Livestock Genetics Program, International Livestock Research Institute (ILRI), Nairobi 00100, Kenya \\ 7 International Center for Agricultural Research in the Dry Areas (ICARDA), Addis Ababa 1108-2010, \\ Ethiopia; j.mwacharo@cgiar.org \\ * Correspondence: zhaoqianjun@caas.cn
}

Received: 27 February 2020; Accepted: 20 April 2020; Published: 30 April 2020

\begin{abstract}
Through long term natural and artificial selection, domestic sheep (Ovis aries) have become adapted to a diverse range of agro-ecological environments and display multiple phenotypic traits. Characterization of diversity and selection signature is essential for genetic improvement, understanding of environmental adaptation, as well as utilization and conservation of sheep genetic resources. Here, we aimed to assess genomic diversity, population structure, and genomic selection among five Chinese native sheep breeds using 600K high density SNP genotypes. A total of 96 animals of the five breeds were selected from different geographical locations with extremely dry or humid conditions. We found a high proportion of informative SNPs, ranging from 93.3\% in Yabuyi to $95.5 \%$ in Wadi, $\mathrm{Hu}$, and Hetian sheep. The average pairwise population differentiation $\left(\mathrm{F}_{\mathrm{ST}}\right)$ between the breeds was $0.048 \%$, ranging from $0.022 \%$ to $0.054 \%$, indicating their low to moderate differentiation. PCA, ADMIXTURE, and phylogenetic tree analyses revealed a clustering pattern of the five Chinese sheep breeds according to their geographical distribution, tail type, coat color, body size, and breeding history. The genomic regions under putative selection identified by $\mathrm{F}_{\mathrm{ST}}$ and XP-EHH approaches frequently overlapped across the breeds, and spanned genes associated with adaptation to extremely dry or humid environments, innate and adaptive immune responses, and growth, wool, milk, and reproduction traits. The present study offers novel insight into genomic adaptation to dry and humid climates in sheep among other domestic animals and provides a valuable resource for further investigation. Moreover, it contributes useful information to sustainable utilization and conservation of sheep genetic resources.
\end{abstract}

Keywords: high density SNPs; genomic diversity; selection sweep; Chinese sheep; adaptation 


\section{Introduction}

Adaptation of livestock breeds to local climatic conditions is an important trait for contemporary agriculture because it reduces environmental stress on animals and leads to an increased and more environmentally friendly production [1]. With around 1000 breeds existing worldwide in various environments, e.g., hot and cold climates, domestic sheep (Ovis aries) are an excellent model to study genetic adaptation. Extreme environmental conditions are a major challenge to livestock production. Changes in climatic conditions, particularly those contributing to weather extremes, like drought or extreme temperature or humidity, may compromise immune functions and thus result in poor reproduction and production performance of domestic animals [2]. Different climate zones have a long-term impact on the adaptive evolution of the major sheep genetic lineages in China [3]. Sheep have spread and become adapted to a wide range of agro-ecological environments, especially those distributed on plateaus or in desert or humid regions, because they are vulnerable to climate change [4,5]. However, the influence of different husbandry cultures on the phenotypes of modern sheep breeds is not well understood. In fact, sheep are uniquely domesticated animals which are managed under production systems with extremely different environmental and agro-ecological conditions (e.g., humid versus dry), they could serve as an appropriate evolutionary model, that allows us to gain novel insight into the understanding of genetic basis on how domestic animals have adapted to extreme environments in a short period of time after their domestication, so that to develop appropriate breeding programs under scenarios of future climate changes [6,7].

Natural selection plays an important role in determining the individuals that are best adapted to any environments. Besides natural selection, artificial selection has been widely applied to livestock species/populations to achieve more desirable and profitable traits [8]. Sheep domestication dates back to the end of the Mesolithic period, 11,000 year ago, making it one of the first domesticated herbivores [9]. Moreover, domestication is the process, following which the protection offered by domestic habitat suppresses the original environmental adaptation. Sheep have played an important role in human society and spread globally [10]. Domestication, natural and artificial selectin have led to marked changes in sheep behavior, appearance, and other important traits [11]. China is rich in sheep resources that have been developed over a long history of sheep breeding [12,13]. Based on the tail type, the Chinese native sheep breeds are divided into five types: Short fat-tailed sheep, long fat-tailed sheep, short thin-tailed sheep, long thin-tailed sheep, and fat-rumped sheep. According to historical, archaeological, and genetic evidence, Mongolian sheep is the common ancestor of Chinese short fat-tailed sheep breeds. Following trading, inter-ethnic wars, and the southward migration of steppe tribes, Mongolian sheep have been introduced into different parts of China, including Gansu, Xinjiang, Qinghai, Henan, Zhejiang, Jiangsu, and Shandong among other provinces. Hu sheep from Jiangsu and Wadi sheep from Shandong belong to Mongolian sheep group [13]. Hetian and Yabuyi sheep are short fat-tailed breeds in Xinjiang while Karakul sheep is an improved breed with a long fat-tail present also in Xinjiang. However, following their distribution from the Mongolian plateau to different agro-ecological regions around almost the entire country, Mongolian sheep have experienced remarkable changes in climatic, environmental, and feeding conditions [13]. All of these factors have the potential to drive the changes in adaptation and selection resulting in microevolution [14,15]. Different breeds belonging to Mongolian sheep group show significant variations in a number of traits, especially related to reproduction, but how these breeds differ genetically in relation to those traits is poorly understood [13]. Genetic diversity represents fundamental basis for adaptation and breeding [16,17]. It is important to document the relative levels of genetic diversity within and between these breeds, so as to provide useful information for breeding and conservation programs.

Detection of signature of selection has potential to reveal new insight into the mechanism of contemporary breeding and artificial selection as well as the causal genes associated with phenotypic variations and important traits. Study on locally adapted breeds is promising to underpin the genes involved in ecologically and economically important traits. Signatures of selection are of great interest in the context of breed differentiation [17]. Several methods for the detection of genomic 
regions that have undergone selection exist and have recently been applied to a number of wild and domestic sheep populations [12,17-28]. Although the genetic basis underlying economically important traits in sheep have been widely studied, our knowledge of the genetic mechanism responsible for adaptation to local environments is still scarce. This study aimed to assess the genomic diversity and population structure, and to detect selection signature in the genomes of the five Chinese local sheep breeds adapted to extremely dry or humid environments using high-density SNP genotyping data. Potential biological functions of the genes with strong selection signals were examined using multi-level bioinformatics approaches.

\section{Materials and Methods}

\subsection{Ethics Statement}

All animal experiments in this study were fully approved by the Animal Care and Use Committee of the Institute of Animals Science, Chinese Academy of Agricultural Sciences (IAS-CAAS) with the following reference number: IASCAAS-AE-03, on 1 September 2014.

\subsection{Samples Collection and DNA Extraction}

A total of 96 Chinese sheep from five diverse indigenous breeds were selected. Ear tissue or whole blood samples were collected from Hetian, Karakul, and Yabuyi sheep distributed in dry environment and $\mathrm{Hu}$ and Wadi sheep in humid environment (Table S1). Ear tissue samples were collected into 2-mL micro-centrifuge tubes with $75 \%$ ethanol. Genomic DNA was extracted from the ear tissue using standard phenol chloroform method. Around $10 \mathrm{~mL}$ of blood was collected from the jugular vein of each animal into vacutainer tubes containing EDTA as anticoagulant and stored in ice/liquid nitrogen $\left(-196^{\circ} \mathrm{C}\right)$. DNA from the whole blood was extracted using DNeasy Blood and Tissue Kit (Qiagen, Dusseldorf, Germany). The concentration and purity of the DNA were measured using NanoDrop 2000 spectrophotometer (Thermo Fisher Scientific Inc., Waltham, MA, USA) and stored at $-20{ }^{\circ} \mathrm{C}$ for genotyping.

\subsection{Genotyping and Quality Control}

The DNA samples were genotyped using Ovine Infinium HD SNP BeadChip (Beijing KPS Biotechnology Co Ltd., China), which contains 606,006 SNPs. We performed quality control (QC) of these SNPs using PLINK v.1.9 software [29] following the criteria listed below [30]. SNPs or individuals were removed if any of the following criteria were met: (1) No chromosomal or physical location; (2) Minor allele frequency (MAF) $<0.05$ within the breeds; (3) SNPs with a call rate $<0.95$; (4) Missing genotyping frequency $>0.02$; and (5) $p$-value for Hardy-Weinberg equilibrium $<0.00001$. After QC filtering, the final dataset consisted of 502,072 autosomal SNPs and 96 animals.

\subsection{Genomic Diversity and Population Structure Analyses}

To understand the population structure within and between the breeds, various parameters related to genomic diversity and population structure, including observed $\left(\mathrm{H}_{\mathrm{O}}\right)$ and expected $\left(\mathrm{H}_{\mathrm{E}}\right)$ heterozygosity for each breed, were calculated with the command -het as implemented in the PLINK, and inbreeding coefficient $\left(\mathrm{F}_{\mathrm{IS}}\right)$ was measured with the command -F also in the PLINK. Genomic relationships represented by the genome-wide proportions of shared identical-by-descent alleles were obtained for each pair of samples using the -genome options in the PLINK. The ADMIXTURE v.1.3. program [31] was employed to determine the population structure clustering based on the optimal number of $\mathrm{K}$ clusters. The number of assumed ancestral genetic clusters $(\mathrm{K})$ ranged from 1 to 10, with 10,000 iterations for each run. Apart from the model-based clustering analysis, we further investigated the population structure using principle component analysis (PCA). To examine the genetic relationships, a neighbor-joining (NJ) phylogenetic tree was reconstructed with Reynold's genetic distances using MEGA7 package [32]. Also, a maximum likelihood (ML) tree was reconstructed using 
RAxML version 8.2.12 program [33] with 1000 bootstrap replicates and the GTRGAMMA model of nucleotide substitution followed by a correction for ascertainment bias (-m ASC_GTRGAMMA-asc-corr = stamatakis $-\mathrm{f}$ a $-\# 1000)$. In addition, pairwise $\mathrm{F}_{\mathrm{ST}}$ values between the breeds were derived using the -fst option in the PLINK. To better understand the population variation, LD decay patterns, which can inform population demography, were investigated for each breed with $\mathrm{r} 2$ values calculated with the parameter -r2-ld-window 1000-ld-window-r2 0 command in the PLINK.

\subsection{Genome-Wide Selection Signatures}

We preformed selection signals across the genomes using fixation index $\left(\mathrm{F}_{\mathrm{ST}}\right)$ and cross population extended haplotype homozygosity (XP-EHH) approaches. We categorized the sheep breeds into two groups: extremely humid (Hu and Wadi sheep) versus extremely dry (Hetian, Krarakul, and Yabuyi sheep) environments as well as short fat-tailed (Yabuyi sheep) versus long fat-tiled (Karakul sheep) groups. The $100 \mathrm{~kb}$ window size with $50 \mathrm{~kb}$ sliding step were used to avoid windows with less than five SNPs, which may bias the estimation of the parameters used to detect selection sweeps [34]. To detect selection signals, we calculated the genome-wide distribution of $\mathrm{F}_{\mathrm{ST}}$ values [35] for each SNP in each window between the groups following previously reported procedures [36]. The $\mathrm{F}_{\mathrm{ST}}$ values were Z-transformed and the $\mathrm{Z}\left(\mathrm{F}_{\mathrm{ST}}\right) \geq 5$ was considered as the threshold to identify selection signatures [18].

We also compared the extended haplotype homozygosity (EHH) between the groups of Chinese local sheep breeds (humid versus dry environments and short-tailed versus long fat-tailed sheep) using the XP-EHH statistic [37] implemented in the rehh package [38]. The XP-EHH tests can evaluate if a given genomic site is homozygosity in one population but polymorphic in another by comparing the EHH scores at one core SNP of the two populations [39], without considering ancestral information. $\mathrm{XP}-\mathrm{EHH}$ of a given focal SNP was defined and standardized according to Sabeti et al. [37] and Gautier et al. [40] and transformed to PXP-EHH following Gautier and Naves [41]. As PXP-EHH may be interpreted as a two-sided $p$-value in a -log10 scale, candidate genomic regions with a $p$-value $\leq 0.01$ $(1 \%)$ were considered as signals of selection in the test. A negative XP-EHH score suggests selection in the reference population while a positive score indicates selection in the observed population. XP-EHH is believed to have a high power in detecting selection signatures with almost or fully fixed haplotypes and also approximately follow a standard normal distribution [37].

\subsection{Annotation of Highly Significant Genomic Regions}

To improve the confidence in the selected outlier windows of putative genomic regions under selection, the top $1 \%$ SNPs showing high statistical significances and which overlapped between $\mathrm{F}_{\mathrm{ST}}$ and XP-EHH analyses were considered. The genomic locations of such SNPs were extended up to $50 \mathrm{~kb}$ upstream and downstream of each of the most significant SNPs to search for overlapping genes based on the version Oar4.0 sheep reference genome assembly (https://www.ncbi.nlm.nih.gov/ assembly/GCA_000298735.2). These genes and their associated annotations were downloaded from the annotated sheep genome in the Ensemble database (https://www.ensemble.org) and used for functional enrichment analysis.

\subsection{Functional Enrichment Analysis of Candidate Genes}

The DAVID platform [42,43] and a web-based toolset: g: profiler (https://biit.cs.ut.ee/gprofiler/ sheep) were used to perform the functional enrichment analysis of the candidate genes under selection. Further investigation of the biological functions of the candidate genes was inferred through a search of literature using the NCBI database (https://www.ncbi.nlm.nih.gov/gene/) to describe the most over-represented pathways and biological processes affected by the candidate genes. 


\section{Results}

\subsection{Genomic Diversity Analysis}

In total, 96 individuals from the five Chinese local sheep breeds sampled in different geographical environments (humid versus dry) (Figure 1) and with unique phenotypic characteristics (short fat-tailed versus long fat-tailed) were genotyped using the 660K Ovine Infinium HD SNP BeadChip. After the QC filtering, the final numbers of animals and SNPs retained for all downstream analyses were 96 and 502,072, respectively. Genomic diversity within each of the five breeds were assessed by estimating the percentage of polymorphic SNPs, $\mathrm{H}_{\mathrm{O}}, \mathrm{H}_{\mathrm{E}}$, minor allele frequency (MAF), and $\mathrm{F}_{\mathrm{IS}}$ (Table 1). The percentages of polymorphic SNPs ranged from 93.5\% in Yabuyi to 95.5\% in Hetian sheep. The average $\mathrm{H}_{\mathrm{O}}$ was the lowest in both Yabuyi and Wadi (0.360) but the highest in Hetian (0.367) sheep. The $\mathrm{H}_{\mathrm{E}}$ ranged from 0.356 in Yabuyi to 0.360 in both Wadi and Hetian sheep. The FIS varied between -0.03 in Karakul and -0.004 in Wadi sheep. The fixation index $\left(\mathrm{F}_{\mathrm{ST}}\right)$ was used to measure of the homogeneity of samples between each breed pair, where the higher value indicates a greater differentiation between the two breeds due to genetic structure. $\mathrm{F}_{\mathrm{ST}}$ ranged from 0.022 between Hetian and Yabuyi sheep to 0.054 between Karakul and Yabuyi (Table S2) sheep.

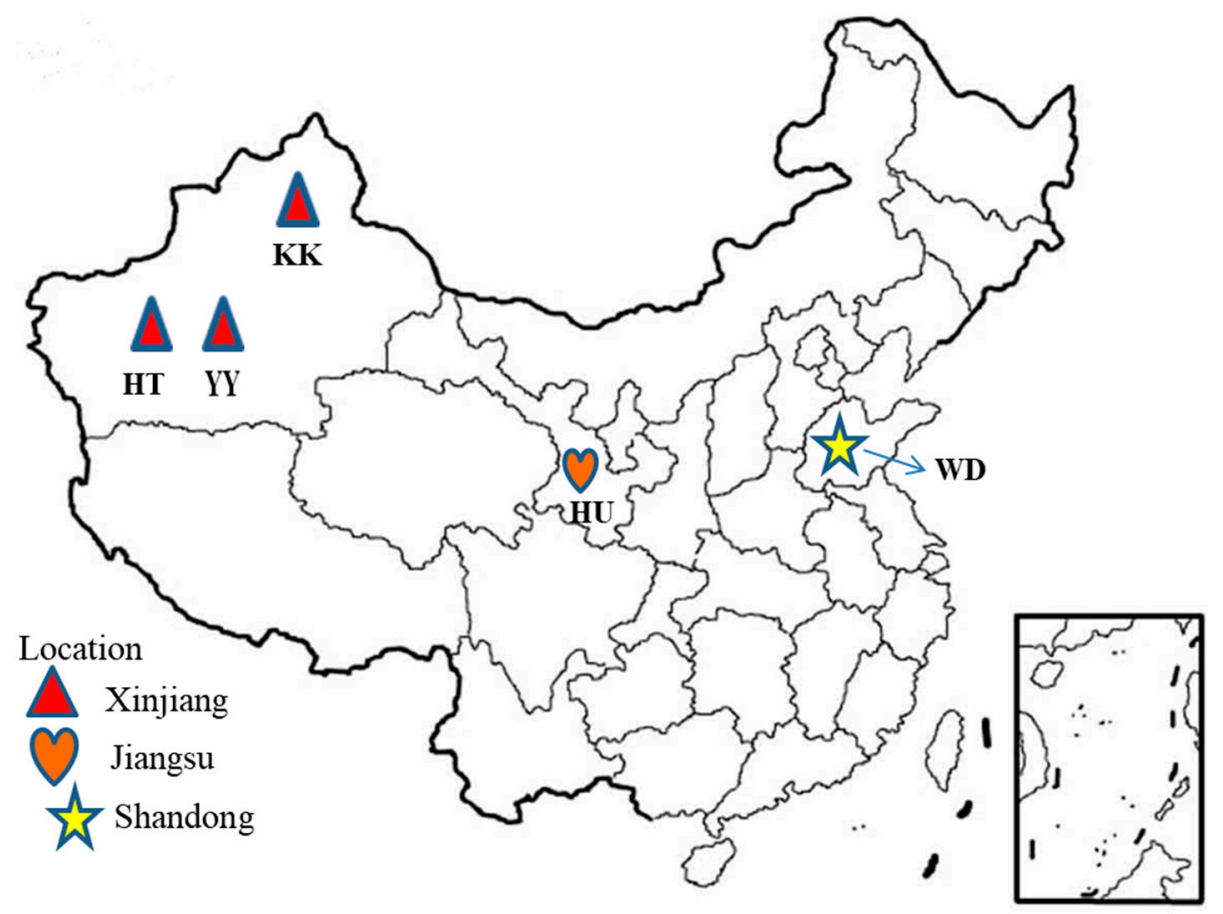

Figure 1. Map of China showing the sampling locations of the five Chinese local sheep breeds analyzed in this study.

Table 1. Summary of genotyped animals and genomic diversity estimates in the five Chinese local sheep breeds.

\begin{tabular}{|c|c|c|c|c|c|c|c|c|c|c|}
\hline Breed & Code & Location & $\begin{array}{c}\text { Sample } \\
\text { Size }\end{array}$ & Ecology & Purpose & $\mathbf{P}_{\mathrm{N}(\%)}$ & $\mathrm{H}_{\mathrm{O}}$ & $\mathbf{H}_{\mathrm{E}}$ & $\mathrm{F}_{\text {IS }}$ & MAF \\
\hline Hetian & HT & Xinjiang & 19 & Arid land & Meat/Wool & 95.5 & 0.367 & 0.360 & -0.02 & 0.269 \\
\hline Karakul & KK & Xinjiang & 20 & Arid/Desert & Lamb skin & 94 & 0.362 & 0.357 & -0.03 & 0.267 \\
\hline Yabuyi & $Y Y$ & Xinjiang & 20 & Arid & Meat & 93.5 & 0.360 & 0.356 & -0.023 & 0.266 \\
\hline Wadi & WD & Shandong & 17 & Sub-humid & Meat/Wool & 95.3 & 0.360 & 0.360 & -0.004 & 0.270 \\
\hline $\mathrm{Hu}$ & $\mathrm{HU}$ & Jiangsu & 20 & Humid & Meat/Lamb skin & 95.2 & 0.364 & 0.358 & -0.029 & 0.268 \\
\hline
\end{tabular}

$\mathrm{P}_{\mathrm{N}}$ : Proportion of polymorphic SNPs; $\mathrm{H}_{\mathrm{O}}$ : Observed heterozygosity; $\mathrm{H}_{\mathrm{E}}$ : Expected heterozygosity; $\mathrm{F}_{\mathrm{IS}}$ : Inbreeding coefficient; MAF: Minor allele frequency. 


\subsection{Population Relationship and Structure Analyses}

To assess the genetic relationship and structure among the five Chinese local sheep breeds, PCA (Figure 2A), ML tree (Figure 2B and Figure S3), NJ tree (Figure S4), and ADMIXTURE (Figure 2D) analyses were performed. The first two principal components, explaining $6.08 \%$ of the total variation, were used to visualize the relationship among the five Chinese sheep breeds from humid and dry environments. The result showed that the breeds from the humid environment (Hu and Wadi sheep) clustered closely together and they were clearly separated from the breeds from the dry environment (Hetian, Karakul, and Yabuyi sheep). Furthermore, the breeds from the dry environment were separated into Hetian and Yabuyi sheep in one group and Karakul sheep in another group, which were in accordance to their coat colors, tailed-types, geographical distribution, and domestication history (Figure 2A). The ML (Figure 2) and NJ (Figure S4) trees indicated that Hu, Wadi, and Karakul sheep were genetically distinct breeds, whereas Hetian sheep seemed to be subdivided into three clusters, of which one cluster aligned with Karakul sheep while the other two clusters mixed with Yabuyi sheep (Figure 2B). However, in the ML-bootstrapping tree (Figure S3), some of these clusters had low values of bootstraps and their subdivisions were thus not fully statistically supported.
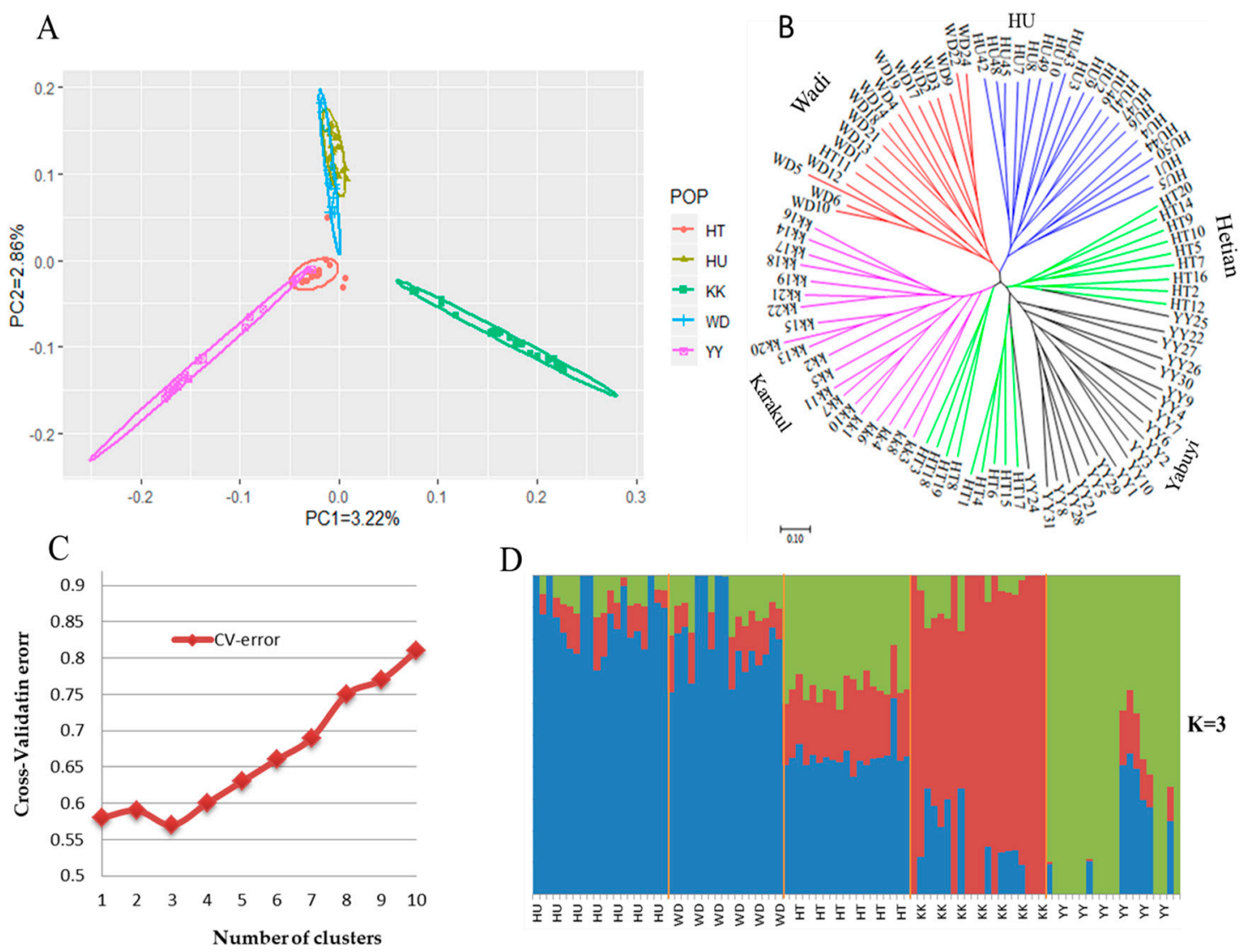

$\mathrm{D}$

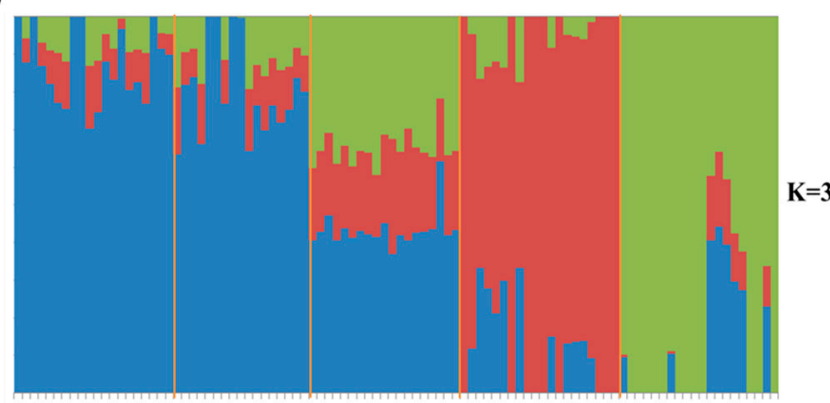

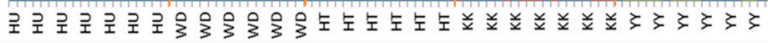

Figure 2. Population relationship and structure analyses of the five Chinese local sheep breeds from extremely dry (HT, YY, and KK) and humid (WD and HU sheep) environments. (A) Principal component (PC) analysis among the 96 sheep of the five breeds. (B) Maximum-likelihood tree reconstructed using the RAxML with the GTRGAMMA model followed by a correction for ascertainment bias.

(C) Cross-validation errors across the 10 assumed ancestral genetic clusters among the five breeds.

(D) Genome-wide admixture proportions at $\mathrm{K}=3$ among the 96 sheep of the five breeds. 
To further analyze the population structure, we investigated population admixture using the ADMIXTURE with $\mathrm{K}$ values ranging from 1 to 10 (Figure 2C and Figure S1). Based on the cross-validation errors, $\mathrm{K}=3$ was identified to be the most optimal number of genetic clusters defining the population structure among the five Chinese local sheep breeds (Figure 2C,D). One genomic cluster was predominant in Hu and Wadi sheep, and the other two clusters were observed in Karakul and Yabuyi sheep. Hetian sheep was the most admixed and showed all the three genetic clusters with none predominating. At $K=4$ and 5, such genetic admixture was observed among all the five sheep breeds (Figure S1).

\subsection{Detection of Selection Signatures}

In this study, we calculated the genome-wide distribution of the $\mathrm{F}_{\mathrm{ST}}$ and $\mathrm{XP}$-EHH values, to explore the selection signatures between the groups of breeds from extreme ecological environments and with different tail types.

Gene ontology (GO) enrichment analysis was performed for the candidate genes revealed in pairwise comparisons between the breeds from extreme (humid versus dry) environments. Several genomic regions with high $\mathrm{F}_{\mathrm{ST}}$ values were detected (Figure 3A). The average $\mathrm{F}_{\mathrm{ST}}$ across the genomes was 0.0377 , indicating little to moderate genetic differentiation according to Wright's classification. In total, 331 outlier windows and 17 genomic regions under selection were detected across the 26 autosomes based on the top $1 \%$ of transformed $Z\left(\mathrm{~F}_{\mathrm{ST}}\right)$ values. The strongest candidate regions were located on chromosomes (OAR)7, OAR6, OAR10, OAR1, OAR4, OAR11, and OAR13, which spanned multiples genes, for instance, TSHR, NAP1L5, RBM26, TSPAN1, VPS50, PEMT, and PCED1A (Table 2 and Table S3). The top three most significant GO terms were associated with endoplasmic reticulum (GO: 0005783; $p$-value $=0.0012)$, regulation of cell growth (GO: 0001558; $p$-value $=0.019)$, and positive regulation of extrinsic apoptotic $(\mathrm{GO}: 1902043 ; p$-value $=0.020)$ terms $($ Table S4).

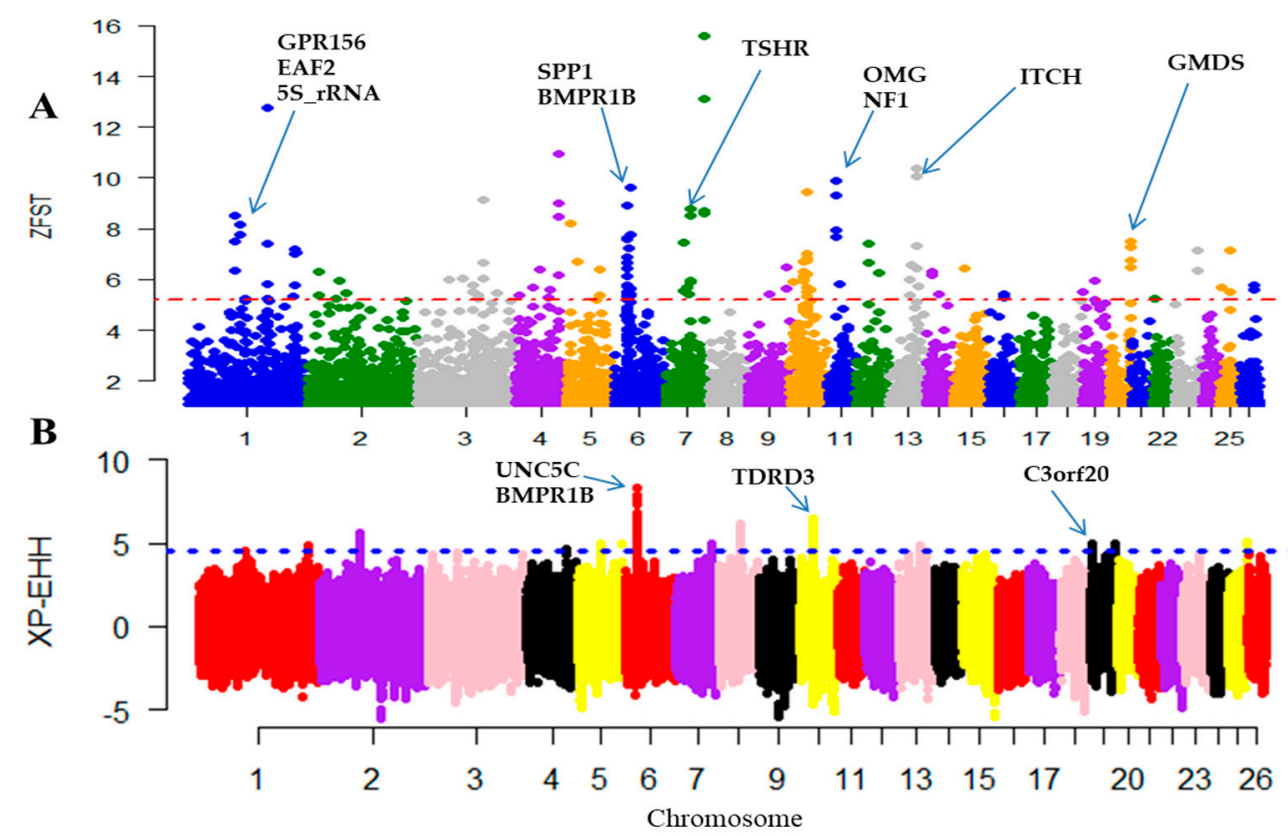

Figure 3. Manhattan plots of selection signatures determined by comparing the five Chinese local sheep breeds from the dry and humid environments using the $\mathrm{Z}\left(\mathrm{F}_{\mathrm{ST}}\right)(\mathbf{A})$ and $\mathrm{XP}-\mathrm{EHH}(\mathbf{B})$ approaches.

We also performed the XP-EHH analysis to reveal genomic regions under selection. In total, 16 candidate regions defined by 351 highest statistically significant SNPs $(p \leq 0.05)$ across the 26 autosomes were identified (Figure 3B). Using the criterion of the top 1\% XP-EHH values, the strongest candidate genomic regions were mapped on OAR6, OAR10, OAR8, and OAR2 and spanned 
multiple genes, such as RASGEF1B, STK24, AGPAT4, and EPB41L4B gene (Table 3 and Table S5). The top three most significant GO terms were associated with post embryonic development (GO: 0009791; $p$-value $=0.0016)$, extracellular matrix structural constituent $(\mathrm{GO}$ : 0005201; $p$-value $=0.0021)$, and ECM-receptor interaction (oas04611; $p$-value $=0.0026)$ (Table S6). Multiple genomic regions with strong selection signatures overlapped between the $\mathrm{F}_{\mathrm{ST}}$ and XP-EHH approaches, for instance, OAR2, OAR6, OAR10, and OAR7 had common genomic regions with several important genes.

Table 2. Candidate genes in the genomic regions of the top 10 highest peak SNPs based on the $\mathrm{F}_{\mathrm{ST}}$ approach.

\begin{tabular}{ccccc}
\hline OAR & Gene Position (bp) & Gene Name & Function & Gene Description \\
\hline 1 & $18,323,4435-18,331,6995$ & GPR156 & Defenses & G protein-coupled receptor 156 \\
1 & $18,456,7855-18,461,9155$ & EAF2 & Disease resistance & 5S ribociated factor 2 \\
1 & $18,334,3776-18,334,3825$ & $5 S \_r R N A$ & Disease resistance & Polycystin 2, transient receptor potential \\
cation channel & Milk production & Secreted phosphoprotein 1 \\
6 & $36,566,367-36,630,153$ & PKD2 & Growth/defense/litter size & Bone morphogenetic protein receptor \\
6 & $36,651,734-36,658,288$ & $S P P 1$ & type 1B \\
6 & $29,361,947-29,448,079$ & SMPR1B & Litter size/fecundity/prolifically & Thyroid stimulating hormone receptor \\
7 & $89,258,424-89,431,877$ & TSHR & Reproduction & Oligodendrocyte myelin glycoprotein \\
11 & $18,317,151-18,318,473$ & OMG & Digestive metabolism & Eurofibromin 1 \\
11 & $18,245,395-18,441,418$ & NF1 & Litter size & Itchy E3 ubiquitin protein ligase \\
13 & $63,388,680-63,446,846$ & $I T C H$ & Disease resistance &
\end{tabular}

Table 3. Candidate genes in the genomic regions of the top 10 highest peak SNPs based on the XP-EHH approach.

\begin{tabular}{ccccc}
\hline OAR & Gene Position (bp) & Gene Name & Function & Gene Description \\
\hline 5 & $49,797,770-49,800,184$ & PCDHGA2 & Immunity & Protocadherin gamma subfamily A, 2 \\
5 & $99,509,492-99,557,151$ & C5orf30 & Disease resistance & Chromosome 5 open reading frame 30 \\
6 & $29,146,028-29,348,864$ & Reproduction & Unc-5 netrin receptor C \\
6 & $29,361,947-29,448,079$ & BMPR1B & Litter size & Bone morphogenetic protein receptor type 1B \\
10 & $75,064,027-75,351,616$ & DOCK9 & Diseases resistant & Dedicator of cytokinesis 9 \\
10 & $18,352,91-20,655,11$ & TDRD3 & Metabolism & Tudor domain containing 3 \\
10 & $29,454,677-29,502,617$ & RXFP2 & Hair/wool & Relaxin family peptide receptor 2 \\
13 & $48,462,232-48,472,599$ & BMP2 & Fecundity & Bone morphogenetic protein 2 \\
19 & $57,395,864-57,446,138$ & C3orf20 & Adaptive immune & Chromosome 3 open reading frame 20 \\
25 & $43,127,841-43,132,260$ & C10orf71 & Adaptive immune & Chromosome 10 open reading frame 71 \\
\hline
\end{tabular}

For the comparison between the short fat-tailed (Yabuyi sheep) and long fat-tailed (Karakul sheep) breeds, multiple genomics regions with high $\mathrm{F}_{\mathrm{ST}}$ values were observed (Figure $4 \mathrm{~A}$ ). In total, 14 candidate regions were defined by 155 high significant SNPs across the 26 autosomes. Considering the top $1 \% \mathrm{~F}_{\mathrm{ST}}$ values, four candidate genomic regions that spanned 25 genes were mapped on OAR2, OAR10, OAR15, and OAR17 (Table 4, Figure 4A). Using the XP-EEH approach, 34 genes embedded in eight candidate genomic regions on OAR24, OAR2, OAR3, OAR9, OAR10, OAR21, and OAR14 were identified from 298 outlier windows across the 26 autosome (Table 5, Figure 4B). The top three most significant GO terms based on the $\mathrm{F}_{\mathrm{ST}}$ approach included nucleoplasm (GO:0005654; $p$-value $=0.011$ ), extracellular exosome (GO:0070062; $p$-value $=0.014)$, and anterior/posterior pattern specification (GO:0070062; $p$-value $=0.017$ ) (Table S7). The top three most significant GO terms based on the $\mathrm{XP}-\mathrm{EHH}$ approach were related to endocytic vesicle (GO:0030139; $p$-value $=0.023$ ), neuronal cell body $(\mathrm{GO}: 0043025 ; p$-value $=0.031)$, and focal adhesion $(\mathrm{GO}: 0005925 ; p$-value $=0.031)$ terms $($ Table S8). 


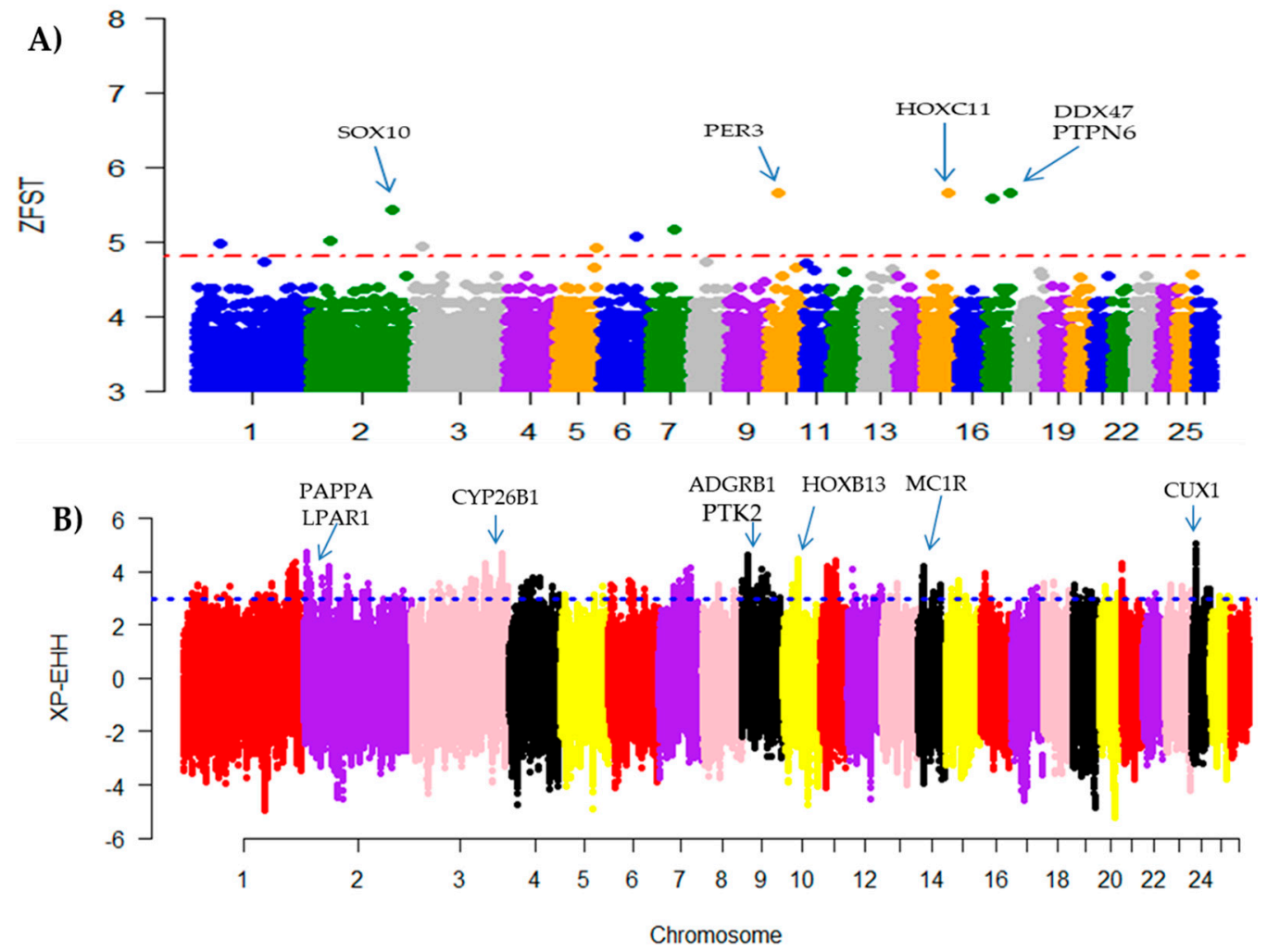

Figure 4. Manhattan plots of genome-wide autosomal $\mathrm{Z}\left(\mathrm{F}_{\mathrm{ST})}(\mathbf{A})\right.$ and $\mathrm{XP}-\mathrm{EHH}(\mathbf{B})$ analyses for the comparison between the short tailed (Yabuyi sheep) and long fat-tailed (Karakul sheep) breeds.

Table 4. The candidate genomic regions and genes identified to be under selection by the $\mathrm{F}_{\mathrm{ST}}$ approach for the comparison between the short fat-tailed (Yabuyi sheep) and long fat-tailed (Karakul sheep) breeds.

\begin{tabular}{|c|c|c|c|}
\hline OAR & Gene Position (bp) & GENE NAME & Function \\
\hline 10 & $35,583,842-35,609,414$ & FAM117A & Reproduction \\
\hline 10 & $78,274,732-78,283,255$ & PER3 & Melatonin and core body temperature rhythms resynchronize \\
\hline 15 & $60,734,22-62,083,71$ & HOXC10 & Regulate cell differentiation \\
\hline 15 & $62,437,71-62,716,81$ & HOXC11 & Tail fat development \\
\hline 15 & $63,382,71-63,384,20$ & HOXC12 & Tail fat development \\
\hline 15 & $63,426,27-64,605,57$ & HOXC13 & Tail fat development \\
\hline 15 & $28,607,005-28,679,716$ & TBK1 & Innate immune response \\
\hline 15 & $28,718,530-28,746,137$ & $\mathrm{ZC} 3 \mathrm{H} 10$ & Tail fat development \\
\hline 15 & $28,757,496-287,993,90$ & $E R B B 3$ & Normal growth and development \\
\hline 15 & $54,582,673-54,583,137$ & $C D K 2$ & Cell cycle regulation, cell proliferation and apoptosis \\
\hline 17 & $22,645,442-22,820,539$ & MMP19 & Proliferation \\
\hline 17 & $29,540,625-29,557,094$ & SNORA53 & Fat tailed development \\
\hline 17 & $29,631,331-29,661,343$ & APAF1 & Immunity \\
\hline 17 & $34,461,385-34,517,413$ & DDX47 & Wool Production \\
\hline 17 & $34,971,013-34,971,123$ & LRP6 & Disease resistance \\
\hline 17 & $53,661,638-53,752,199$ & PHB2 & Immunoprecipitation and embryo developments \\
\hline 17 & $53,803,322-53,859,050$ & oar-mir-200c & Milk production \\
\hline 17 & $53,875,546-53,895,506$ & PTPN6 & Metabolism \\
\hline 2 & $58,319,311-58,656,152$ & LGALS2 & Disease resistance \\
\hline 2 & $10,409,016,7-10,410,456,3$ & H1-0 & Antibodies \\
\hline 2 & $10,481,607,5-10,500,749,7$ & GCAT & Regulate cardiac development \\
\hline 2 & $17,658,885,2-17,728,788,6$ & SOX10 & Coat color patterns \\
\hline 2 & $18,434,313,9-18,434,327,5$ & CRPPA & Red meat production \\
\hline 2 & $19,005,983,1-19,006,799,7$ & RELN & Fat tailed deposition \\
\hline
\end{tabular}


Table 5. The candidate genomic regions and genes identified to be under selection by the XP-EHH approach for the comparison between the short fat-tailed (Yabuyi sheep) and log fat-tailed (Karakul sheep) breeds.

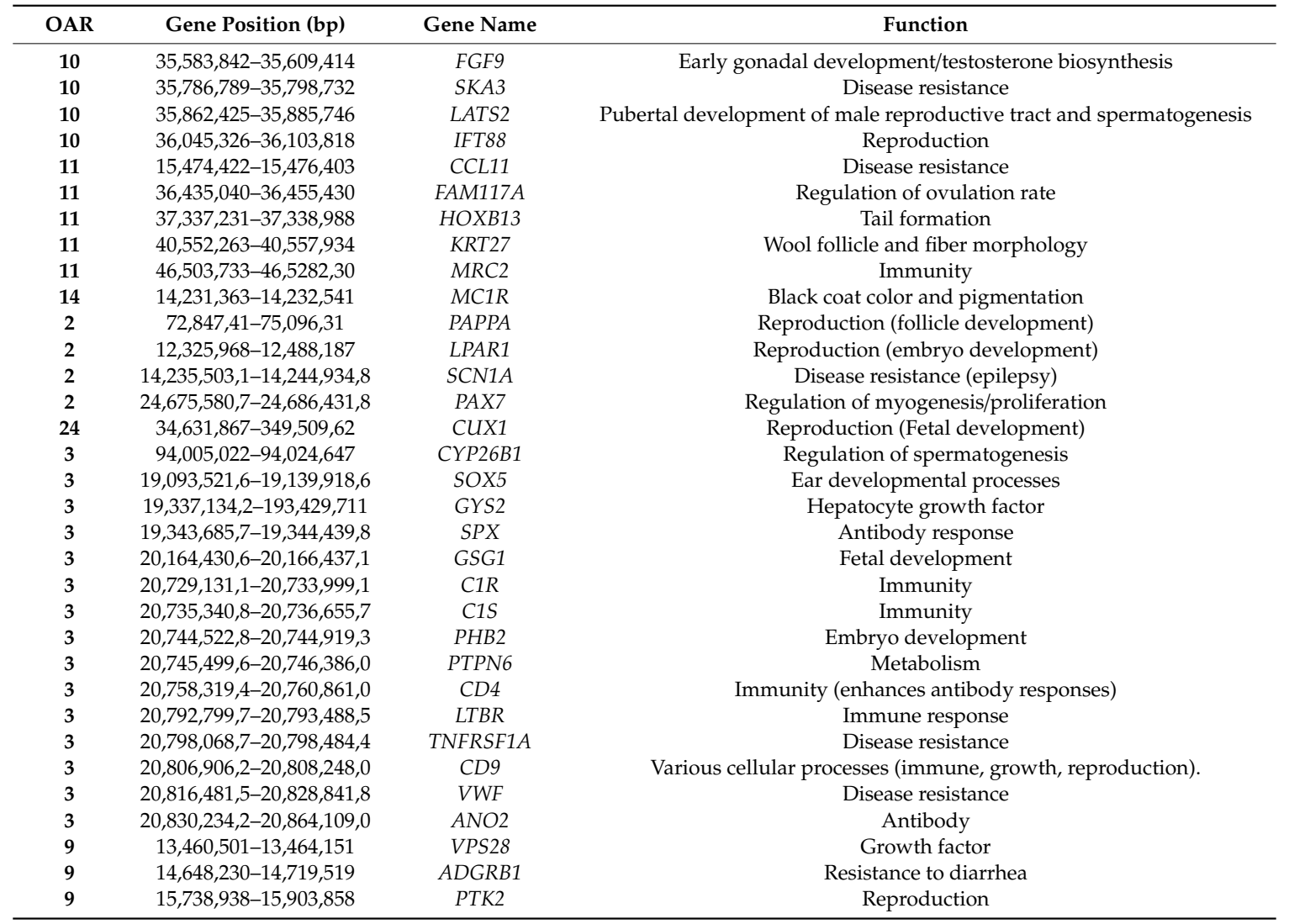

\section{Discussion}

In the present study, population genomic diversity and genome-wise selection signature analyses were conducted using the 600K SNP genotypes of 96 animals from the five Chinese local sheep breeds adapted to extremely humid and dry environments. We evaluated their population structure using the PCA, ADMIXTURE, and ML and NJ phylogenetic trees. In addition, genome-wide scan of selection signals were analyzed using the $\mathrm{F}_{\mathrm{ST}}$ and $\mathrm{XP}-\mathrm{EHH}$ approaches. The results indicated low to moderate genetic variation among the studied sheep breeds. The five Chinese local sheep breeds were divided into three genetic clusters according to their coat colors, body sizes, tail types, geographical locations, and breeding history. Furthermore, multiple genomic regions carrying important candidate genes for adaptation to dry or humid environments were detected.

\subsection{Genomic Diversity within Breeds}

Assessing the within-breed/population genetic variability could provide insight for designing breeding improvement strategies for local sheep genetic resources [12,44]. Hetian, Wadi, and Hu sheep displayed the highest polymorphisms, followed by Karakul and Yabuyi sheep (Table 1). Furthermore, the lowest pairwise differentiation was observed between Yabuyi and Hetain sheep but the highest differentiation was between Yabuyi and Karakul sheep (Table S2). Generally, the levels of genetic polymorphisms in sheep from the humid environment were higher compared to sheep from the dry environment. The $\mathrm{H}_{\mathrm{O}}$ and $\mathrm{H}_{\mathrm{E}}$ in Wadi sheep were the same, which might be related to random mating in this breed [45]. In Hetian, $\mathrm{Hu}$, Karakul, and Yabuyi breeds, the $\mathrm{H}_{\mathrm{O}}$ were higher $\mathrm{H}_{\mathrm{E}}$ because of regular exchange of breeding rams among flocks within the breeds $[45,46]$. The lowest genetic diversity was observed in Yabuyi sheep, which could be due to inbreeding following its relatively small population 
size in an isolated geographical location. Genetic diversity of these five Chinese sheep breeds were higher compared to those observed in Ethiopian fat-tailed sheep [25] and South African indigenous sheep [47], but lower than that of Morada Nova hair sheep breeds in Brazil [48].

\subsection{Population Structure of Chinese Local Sheep Breeds from Dry and Humid Environments}

The PCA, ML and NJ phylogenetic trees, and ADMIXTURE analyses all revealed a common clustering pattern that showed a clear separation between the breeds from humid and dry environments. This pattern may be related to their grazing management and breeding history. Furthermore, the PCA analysis revealed the 96 individuals clustering into three groups on the bases of genetic relationships following their tail types, body sizes and coat colors [12]. Additionally, we found that MAF in different sheep breeds distributed in dry and humid environments were very similar. This result was supported by the low to moderate pairwise $\mathrm{F}_{\mathrm{ST}}$ differentiations between these breeds. Moreover, breeds form the dry environment formed two separated groups, corresponding to their tail shapes, coat colors, body sizes, and breeding history (Table S1) [12,49,50]. Wadi, Karakul, and Yabuyi sheep displayed the highest LD decay, while Hetian and Hu sheep showed the lowest LD across all genomic distance intervals (Figure S2). In general, the mean $\mathrm{r} 2$ values decreased rapidly with increasing genomic distances and attained constantly after 200-300 Kb. The most rapid decrease in $\mathrm{r} 2$ was observed in the first five bins, the phenomenon could be due to admixture effects, which was similar with the result previously reported by Gibbs et al. [51].

\subsection{Selection Signatures of Candidate Genes}

Using the $\mathrm{F}_{\mathrm{ST}}$ and XP-EHH approaches, we identified various genomic regions that are potentially under selection in at least one of the five sheep breeds. It is well known that the detection of common selection signatures by more than one methodology can provide stronger evidence of selection in particular genomic regions [52,53].

\subsubsection{Candidate Genes Related to Immune Response and Disease Resistance}

Several overlapping genes involved in regulating innate and adaptive immunity in mammals were identified; for example, HERC2 and CYFIP1 genes that are relevant to regulate innate and acquired immune responses, as well as cytokine signaling [54]. Multiples candidate genes were also found to participate in host defense mechanism, resistance diseases, and inflammatory responses, with two most significant genes worth to mention as examples. C5orf30 gene was reported in association with the development of autoimmune disorders in primary biliary cirrhosis as well as the susceptibility and severity of rheumatoid arthritis in humans [55,56]. Another interesting gene is ITCH, which encodes a member of the Nedd4 family of HECT domain E3 ubiquitin ligases and plays a role in protein trafficking and immune response, and in several signaling pathways that regulate cellular growth and proliferation in multiple processes [57]. A bi-allelic mutation in ITCH gene was observed to cause a severe syndromic multisystem autoimmune disease [58].

\subsubsection{Candidate Genes Associated with Body Weight and Digestive Metabolism Traits}

Growth and body weight are the most economically important traits in livestock breeds that are specialized for meat production. Several breeds from dry or tropical environments tend to have small body weight/size and slow growth rate compared to humid or temperate breeds [59]. Body weight is one of important traits for meat type animals that can be measured at birth or other life stages. Hence, natural and artificial selection may have left traces in the genomic regions harboring genes involved in the production traits of the Chinese sheep from humid and dry environments. We found overlapped candidate genes mapped on OAR6, OAR11, and OAR10. For example, GJB2 and GJA3 genes were found to be related to body size and development [19]. PKD2 gene has been associated with milk production traits [12] and OMG gene was involved in metabolism following food deprivation [60]. Centrosomal P4.1-associated protein $(C P A P)$ was shown to be involved in the assembly of centrioles 
and plays a structural role in the maintenance of centrosome function, such as centrosome integrity and normal spindle morphology during cell division, motility, or intracellular traffic [61].

\subsubsection{Candidate Genes Associated to Reproduction Traits}

Reproduction is a critically important trait in livestock breeding [62] and in the sheep industry particularly $[63,64]$. It appears to be controlled by multiple genes and factors $[65,66]$, impacting on pathways of ovarian follicular development, embryogenesis, oocyte maturation, ovulation, fertilization, and uterine receptivity.

Interestingly, the most statistically significant gene identified by the comparison of sheep between extreme (dry versus humid) environments was BMPR1B, which plays a major role in sheep reproduction and appears in a candidate region on OAR6, that was identified by both $\mathrm{F}_{\mathrm{ST}}$ and XP-EHH approaches. $B M P R 1 B$ gene is already best-documented for its significant association with prolificacy in sheep [67-69] and directly determines litter size in other mammals [70]. TSHR gene was identified to be involved in reproduction [20] and NF1 gene to be associated with litter size [71]. Finally, BMP2 gene was suggested to be involved in sheep prolificacy and fecundity $[72,73]$.

\section{Conclusions}

In this study, our results revealed low to moderate levels of genetic variability among the five Chinese local sheep breeds distributed in extremely dry and humid environments. Moreover, the five breeds could be divided into three genetic clusters, including breeds from humid environment being one cluster and another two clusters of breeds from the dry environment, following primarily their tail types and geographical distributions. Selection signature analysis identified various candidate genomic regions spanning genes related to skeletal structure and morphology, body temperature regulation, disease resistance, reproduction, and possibly adaptation to local environments. Our findings will provide valuable information to support genomic improvement of these local sheep breeds towards better adaptation to and an increased performance in the extremely dry and humid environments.

Supplementary Materials: The following supplementary materials are available online at http://www.mdpi.com/ 2073-4425/11/5/494/s1. Figure S1. Population structuring among the five Chinese local sheep breeds analyzed by the ADMIXTURE program. Figure S2. Linkage disequilibrium (LD) decay by genomic distances between SNPs in the five Chinese local sheep breeds. Figure S3. Maximum-likelihood phylogenetic tree of the five Chinese local sheep breeds reconstructed using the RAxML software with the GTRGAMMA model followed by a correction for ascertainment bias. Figure S4. A neighbor-joining phylogenetic tree of the five Chinese local sheep breeds reconstructed using the MEGA7 package. Table S1. Description of the five Chinese local sheep breeds and their agro-ecological locations. Table S2. Pairwise population differentiation $\left(\mathrm{F}_{\mathrm{ST}}\right)$ between the five Chinese local sheep breeds. Table S3. The top $1 \%$ candidate genes detected by the $\mathrm{Z}\left(\mathrm{F}_{\mathrm{ST})}\right.$ approach. Table $\mathrm{S} 4$. GO terms and KEGG pathways of the top $1 \% \mathrm{Z}\left(\mathrm{F}_{\mathrm{ST}}\right)$ values. Table S5. Candidate genes detected by the top $1 \% \mathrm{XP}-\mathrm{EHH}$ values. Table S6. GO terms and KEGG pathways of the top $1 \%$ XP-EHH values. Table S7. GO terms identified based on the $\mathrm{F}_{\mathrm{ST}}$ approach between the short fat-tailed (Yabuyi sheep) and long fat-tailed (Karakul sheep) breeds. Table S8. GO terms identified based on the XP-EHH approach between the short fat-tailed (Yabuyi sheep) and long fat-tailed (Karakul sheep) breeds.

Author Contributions: Conceptualization, A.A. and Y.M.; data curation, A.A. and A.B.; formal analysis, A.A.; funding acquisition, Y.M.; investigation, A.A.; methodology, A.A., A.B., F.B., X.X., F.X., and G.G.; project administration, Y.M.; resources, Y.P. and F.X.; software, A.A. and X.X.; supervision, J.M.M., J.-L.H., Q.Z., and Y.M.; visualization, A.A.; writing—original draft, A.A.; writing—review and editing, S.M.A.A., J.-L.H., J.M.M., and Q.Z. All authors have read and agreed to the published version of the manuscript.

Funding: This project was funded by the Science and Technology Innovation Project of the Chinese Academy of Agricultural Sciences (ASTIP-IAS01) and Modern Cashmere Sheep Industry System (CARS-39-01).

Acknowledgments: The authors would like to express their gratitude to all those who helped us during the project and the writing of this paper.

Conflicts of Interest: The authors declare no conflict of interest.

Data Accessibility: The datasets analyzed on this study are available upon request from corresponding authors. 


\section{References}

1. Berman, A. Invited review: Are adaptations present to support dairy cattle productivity in warm climates? J. Dairy Sci. 2011, 94, 2147-2158. [CrossRef] [PubMed]

2. St-Pierre, N.R.; Cobanov, B.; Schnitkey, G. Economic losses from heat stress by US livestock industries. J. Dairy Sci. 2003, 86, E52-E77. [CrossRef]

3. Yang, J.; Li, W.-R.; Lv, F.-H.; He, S.-G.; Tian, S.-L.; Peng, W.-F.; Sun, Y.-W.; Zhao, Y.-X.; Tu, X.-L.; Zhang, M. Whole-genome sequencing of native sheep provides insights into rapid adaptations to extreme environments. Mol. Biol. Evol. 2016, 33, 2576-2592. [CrossRef] [PubMed]

4. Easterling, D.R.; Meehl, G.A.; Parmesan, C.; Changnon, S.A.; Karl, T.R.; Mearns, L.O. Climate extremes: Observations, modeling, and impacts. Science 2000, 289, 2068-2074. [CrossRef] [PubMed]

5. Lv, F.-H.; Peng, W.-F.; Yang, J.; Zhao, Y.-X.; Li, W.-R.; Liu, M.-J.; Ma, Y.-H.; Zhao, Q.-J.; Yang, G.-L.; Wang, F. Mitogenomic meta-analysis identifies two phases of migration in the history of eastern Eurasian sheep. Mol. Biol. Evol. 2015, 32, 2515-2533. [CrossRef]

6. Howden, S.M.; Soussana, J.-F.; Tubiello, F.N.; Chhetri, N.; Dunlop, M.; Meinke, H. Adapting agriculture to climate change. Proc. Natl. Acad. Sci. USA 2007, 104, 19691-19696. [CrossRef]

7. Lobell, D.B.; Burke, M.B.; Tebaldi, C.; Mastrandrea, M.D.; Falcon, W.P.; Naylor, R.L. Prioritizing climate change adaptation needs for food security in 2030. Science 2008, 319, 607-610. [CrossRef]

8. Brito, L.F.; Kijas, J.W.; Ventura, R.V.; Sargolzaei, M.; Porto-Neto, L.R.; Cánovas, A.; Feng, Z.; Jafarikia, M.; Schenkel, F.S.J.B.G. Genetic diversity and signatures of selection in various goat breeds revealed by genome-wide SNP markers. BMC Genome 2017, 18, 229. [CrossRef]

9. Chessa, B.; Pereira, F.; Arnaud, F.; Amorim, A.; Goyache, F.; Mainland, I.; Kao, R.R.; Pemberton, J.M.; Beraldi, D.; Stear, M.J.J.S. Revealing the history of sheep domestication using retrovirus integrations. Science 2009, 324, 532-536. [CrossRef]

10. Pan, Z.; Li, S.; Liu, Q.; Wang, Z.; Zhou, Z.; Di, R.; Miao, B.; Hu, W.; Wang, X.; Hu, X. Whole-genome sequences of 89 Chinese sheep suggest role of RXFP2 in the development of unique horn phenotype as response to semi-feralization. GigaScience 2018, 7, giy019. [CrossRef]

11. Chen, S.Y.; Duan, Z.Y.; Sha, T.; Xiangyu, J.; Wu, S.F.; Zhang, Y.P. Origin, genetic diversity, and population structure of Chinese domestic sheep. Gene 2006, 376, 216-223. [CrossRef]

12. Wei, C.; Wang, H.; Liu, G.; Wu, M.; Cao, J.; Liu, Z.; Liu, R.; Zhao, F.; Zhang, L.; Lu, J.; et al. Genome-wide analysis reveals population structure and selection in Chinese indigenous sheep breeds. BMC Genome 2015, 16, 194. [CrossRef]

13. Du, L.; Li, J.; Ma, N.; Ma, Y.; Wang, J.; Yin, C.; Luo, J.; Liu, N.; Jia, Z.; Fu, C. Animal Genetic Resources in China: Sheep and Goats; China Agriculture Press: Beijing, China, 2011.

14. Olson, D.M.; Dinerstein, E.; Wikramanayake, E.D.; Burgess, N.D.; Powell, G.V.; Underwood, E.C.; D'amico, J.A.; Itoua, I.; Strand, H.E.; Morrison, J.C.J.B. Terrestrial ecoregions of the world: A New Map of Life on Earth: A new global map of terrestrial ecoregions provides an innovative tool for conserving biodiversity. BioScience 2001, 51, 933-938. [CrossRef]

15. Karell, P.; Ahola, K.; Karstinen, T.; Valkama, J.; Brommer, J.E. Climate change drives microevolution in a wild bird. Nat. Commun. 2011, 2, 208. [CrossRef] [PubMed]

16. Qanbari, S.; Simianer, H.J.L.S. Mapping signatures of positive selection in the genome of livestock. Livest. Sci. 2014, 166, 133-143. [CrossRef]

17. Kijas, J.W.; Lenstra, J.A.; Hayes, B.; Boitard, S.; Porto Neto, L.R.; San Cristobal, M.; Servin, B.; McCulloch, R.; Whan, V.; Gietzen, K.; et al. Genome-wide analysis of the world's sheep breeds reveals high levels of historic mixture and strong recent selection. PLoS Biol. 2012, 10, e1001258. [CrossRef]

18. Fariello, M.-I.; Servin, B.; Tosser-Klopp, G.; Rupp, R.; Moreno, C.; San Cristobal, M.; Boitard, S. Selection signatures in worldwide sheep populations. PLoS ONE 2014, 9, e103813. [CrossRef] [PubMed]

19. Kim, E.-S.; Elbeltagy, A.; Aboul-Naga, A.M.; Rischkowsky, B.; Sayre, B.; Mwacharo, J.M.; Rothschild, M.F. Multiple genomic signatures of selection in goats and sheep indigenous to a hot arid environment. Heredity 2016, 116, 255-264. [CrossRef] [PubMed]

20. Liu, Z.; Ji, Z.; Wang, G.; Chao, T.; Hou, L.; Wang, J.J.B. Genome-wide analysis reveals signatures of selection for important traits in domestic sheep from different ecoregions. BMC Genome 2016, 17, 863. [CrossRef] [PubMed] 
21. Purfield, D.C.; McParland, S.; Wall, E.; Berry, D.P. The distribution of runs of homozygosity and selection signatures in six commercial meat sheep breeds. PLoS ONE 2017, 12, e0176780. [CrossRef]

22. De Simoni Gouveia, J.J.; Paiva, S.R.; McManus, C.M.; Caetano, A.R.; Kijas, J.W.; Facó, O.; Azevedo, H.C.; de Araujo, A.M.; de Souza, C.J.H.; Yamagishi, M.E.B.; et al. Genome-wide search for signatures of selection in three major Brazilian locally adapted sheep breeds. Livest. Sci. 2017, 197, 36-45. [CrossRef]

23. Gutierrez-Gil, B.; Arranz, J.J.; Pong-Wong, R.; García-Gámez, E.; Kijas, J.; Wiener, P. Application of selection mapping to identify genomic regions associated with dairy production in sheep. PLoS ONE 2014, 9, e94623. [CrossRef] [PubMed]

24. Mastrangelo, S.; Tolone, M.; Sardina, M.T.; Sottile, G.; Sutera, A.M.; Di Gerlando, R.; Portolano, B.J.G.S.E. Genome-wide scan for runs of homozygosity identifies potential candidate genes associated with local adaptation in Valle del Belice sheep. Genet. Sel. Evol. 2017, 49, 84. [CrossRef] [PubMed]

25. Ahbara, A.; Bahbahani, H.; Almathen, F.; Al Abri, M.; Agoub, M.O.; Abeba, A.; Kebede, A.; Musa, H.H.; Mastrangelo, S.; Pilla, F.; et al. Genome-wide variation, candidate regions and genes associated with fat deposition and tail morphology in Ethiopian indigenous sheep. Front. Genet. 2019, 9, 699. [CrossRef] [PubMed]

26. Megdiche, S.; Mastrangelo, S.; Hamouda, M.B.; Lenstra, J.A.; Ciani, E. A combined multi-cohort approach reveals novel and known genome-wide selection signatures for wool traits in Merino and Merino-derived sheep breeds. Front. Genet. 2019, 10, 1025. [CrossRef]

27. Signer-Hasler, H.; Burren, A.; Ammann, P.; Drögemüller, C.; Flury, C. Runs of homozygosity and signatures of selection: A comparison among eight local Swiss sheep breeds. Anim. Genet. 2019, 50, 512-525. [CrossRef]

28. Hu, X.-J.; Yang, J.; Xie, X.-L.; Lv, F.-H.; Cao, Y.-H.; Li, W.-R.; Liu, M.-J.; Wang, Y.-T.; Li, J.-Q.; Liu, Y.-G. The genome landscape of Tibetan sheep reveals adaptive introgression from argali and the history of early human settlements on the Qinghai-Tibetan Plateau. Mol. Biol. 2019, 36, 283-303. [CrossRef]

29. Purcell, S.; Neale, B.; Todd-Brown, K.; Thomas, L.; Ferreira, M.A.; Bender, D.; Maller, J.; Sklar, P.; De Bakker, P.I.; Daly, M.J. PLINK: A tool set for whole-genome association and population-based linkage analyses. Am. J. Hum. Genet. 2007, 81, 559-575. [CrossRef]

30. Zhang, Q.; Calus, M.P.; Guldbrandtsen, B.; Lund, M.S.; Sahana, G.J.B. Estimation of inbreeding using pedigree, 50k SNP chip genotypes and full sequence data in three cattle breeds. BMC Genet. 2015, 16, 88 . [CrossRef]

31. Alexander, D.H.; Novembre, J.; Lange, K.J.G. Fast model-based estimation of ancestry in unrelated individuals. Genome Res. 2009, 19, 1655-1664. [CrossRef]

32. Kumar, S.; Stecher, G.; Tamura, K. MEGA7: Molecular evolutionary genetics analysis version 7.0 for bigger datasets. Mol. Biol. Evol. 2016, 33, 1870-1874. [CrossRef] [PubMed]

33. Stamatakis, A. RAxML version 8: A tool for phylogenetic analysis and post-analysis of large phylogenies. Bioinformatics 2014, 30, 1312-1313. [CrossRef]

34. Axelsson, E.; Ratnakumar, A.; Arendt, M.-L.; Maqbool, K.; Webster, M.T.; Perloski, M.; Liberg, O.; Arnemo, J.M.; Hedhammar, Å.; Lindblad-Toh, K.J.N. The genomic signature of dog domestication reveals adaptation to a starch-rich diet. Nature 2013, 495, 360-364. [CrossRef] [PubMed]

35. Weir, B.S.; Cockerham, C.C.J. Estimating F-statistics for the analysis of population structure. Evolution 1984, 38, 1358-1370. [PubMed]

36. Zhi, D.; Da, L.; Liu, M.; Cheng, C.; Zhang, Y.; Wang, X.; Li, X.; Tian, Z.; Yang, Y.; He, T.J. Whole genome sequencing of Hulunbuir short-tailed sheep for identifying candidate genes related to the short-tail phenotype. G3 Genes Genom. Genet. 2018, 8, 377-383. [CrossRef] [PubMed]

37. Sabeti, P.C.; Varilly, P.; Fry, B.; Lohmueller, J.; Hostetter, E.; Cotsapas, C.; Xie, X.; Byrne, E.H.; McCarroll, S.A.; Gaudet, R.J.N. Genome-wide detection and characterization of positive selection in human populations. Nature 2007, 449, 913-918. [CrossRef]

38. Gautier, M.; Vitalis, R.J.B. Rehh: An R package to detect footprints of selection in genome-wide SNP data from haplotype structure. Bioinformatics 2012, 28, 1176-1177. [CrossRef]

39. Ma, Y.; Ding, X.; Qanbari, S.; Weigend, S.; Zhang, Q.; Simianer, H.J.H. Properties of different selection signature statistics and a new strategy for combining them. Heredity 2015, 115, 426-436. [CrossRef]

40. Gautier, M.; Klassmann, A.; Vitalis, R. Rehh 2.0: A reimplementation of the R package rehh to detect positive selection from haplotype structure. Mol. Ecol. Resour. 2017, 17, 78-90. [CrossRef] 
41. Gautier, M.; Naves, M.J.M. Footprints of selection in the ancestral admixture of a New World Creole cattle breed. Mol. Ecol. 2011, 20, 3128-3143. [CrossRef]

42. Huang, D.; Sherman, B.; Lempicki, R. Systematic and integrative analysis of large gene lists using DAVID Bioinformatics Resources. Nat. Protoc. 2009, 4, 44-57. [CrossRef]

43. Huang, D.W.; Sherman, B.T.; Lempicki, R.A.J.N. Bioinformatics enrichment tools: paths toward the comprehensive functional analysis of large gene lists. Nucleic Acids Res. 2009, 37, 1-13. [CrossRef]

44. Getachew, T.; Haile, A.; Mészáros, G.; Rischkowsky, B.; Huson, H.J.; Gizaw, S.; Wurzinger, M.; Mwai, A.O.; Sölkner, J. Genetic diversity, population structure and runs of homozygosity in Ethiopian short fat-tailed and Awassi sheep breeds using genome-wide 50k SNP markers. Livest. Sci. 2020, 232, 103899. [CrossRef]

45. Oliveira, J.C.V.; Ribeiro, M.N.; Rocha, L.L.; Gomes-Filho, M.A.; Delgado, J.V.; Martinez, A.M.; Menezes, M.P.C.; Bettencourt, C.M.; Gama, L.T. Genetic relationships between two homologous goat breeds from Portugal and Brazil assessed by microsatellite markers. Small Rumin. Res. 2010, 93, 79-87. [CrossRef]

46. Ojango, J.M.; Mpofu, N.; Marshall, K.; Andersson-Eklund, L. Quantitative methods to improve the understanding and utilization of animal genetic resources. Anim. Genet. Train. Resour. 2011, 3, 2011.

47. Sandenbergh, L.; Cloete, S.W.P.; Roodt-Wilding, R.; Snyman, M.A.; Van der Merwe, A.E. Genetic Diversity and Population Structure of Four South African Sheep Breeds. Proc. Assoc. Advmt. Anim. Breed. Genet 2015, 21, 294-297.

48. David, C.M.G.; Quirino, C.R.; Vega, W.H.O.; Bartholazzi Junior, A.; Madella-Oliveira, A.F.; Costa, R.L.D. Diversity of indigenous sheep of an isolated population. BMC Vet. Res. 2018, 14, 350. [CrossRef] [PubMed]

49. Wei, C.; Wang, H.; Liu, G.; Zhao, F.; Kijas, J.W.; Ma, Y.; Lu, J.; Zhang, L.; Cao, J.; Wu, M.; et al. Genome-wide analysis reveals adaptation to high altitudes in Tibetan sheep. Sci. Rep. 2016, 6, 26770. [CrossRef]

50. Zeng, X.C.; Chen, H.Y.; Hui, W.Q.; Jia, B.; Du, Y.C.; Tian, Y.Z. Genetic diversity measures of 8 local sheep breeds in Northwest of China for genetic resource conservation. Asian Aust. J. Anim. Sci. 2010, 23, 1552-1556. [CrossRef]

51. Gibbs, R.A. Genome-wide survey of SNP variation uncovers the genetic structure of cattle breeds. Science 2009, 324, 528-532. [PubMed]

52. Hohenlohe, P.A.; Phillips, P.C.; Cresko, W.A.J.I. Using population genomics to detect selection in natural populations: Key concepts and methodological considerations. Int. J. Plant Sci. 2010, 171, 1059-1071. [CrossRef] [PubMed]

53. Oleksyk, T.K.; Smith, M.W.; O’Brien, S.J. Genome-wide scans for footprints of natural selection. Biol. Sci. 2010, 365, 185-205. [CrossRef]

54. Al Kalaldeh, M.; Gibson, J.; Lee, S.H.; Gondro, C.; Van Der Werf, J.H.J. Detection of genomic regions underlying resistance to gastrointestinal parasites in Australian sheep. Genet. Sel. Evol. 2019, 51, 37. [CrossRef] [PubMed]

55. Dorris, E.R.; Linehan, E.; Trenkmann, M.; Veale, D.J.; Fearon, U.; Wilson, A.G. Association of the rheumatoid arthritis severity variant rs26232 with the invasive activity of synovial fibroblasts. Cells 2019, 8, 1300. [CrossRef] [PubMed]

56. Dorris, E.R.; Tazzyman, S.J.; Moylett, J.; Ramamoorthi, N.; Hackney, J.; Townsend, M.; Muthana, M.; Lewis, M.J.; Pitzalis, C.; Wilson, A.G. The autoimmune susceptibility gene C5orf30 regulates macrophage-mediated resolution of inflammation. J. Immunol. 2019, 202, ji1801155. [CrossRef] [PubMed]

57. Rotin, D.; Kumar, S. Physiological functions of the HECT family of ubiquitin ligases. Nat. Rev. Mol. Cell Biol. 2009, 10, 398-409. [CrossRef]

58. Kleine-Eggebrecht, N.; Staufner, C.; Kathemann, S.; Elgizouli, M.; Kopajtich, R.; Prokisch, H.; Lainka, E. Mutation in ITCH gene can cause syndromic multisystem autoimmune disease with acute liver failure. Pediatrics 2019, 143, e20181554. [CrossRef]

59. Mwacharo, J.M.; Kim, E.-S.; Elbeltagy, A.R.; Aboul-Naga, A.M.; Rischkowsky, B.A.; Rothschild, M.F. Genomic footprints of dryland stress adaptation in Egyptian fat-tail sheep and their divergence from East African and western Asia cohorts. Sci. Rep. 2018, 7, 1-10. [CrossRef]

60. Gabel, G.; Aschenbach, J. Influence of food deprivation on the transport of 3-O-methyl- $\alpha$-D-glucose across the isolated ruminal epithelium of sheep. J. Anim. Sci. 2002, 80, 2740-2746. [CrossRef]

61. Cormier, A.; Clément, M.-J.; Knossow, M.; Lachkar, S.; Savarin, P.; Toma, F.; Sobel, A.; Gigant, B.; Curmi, P.A. The PN2-3 domain of centrosomal P4.1-associated protein implements a novel mechanism for tubulin sequestration. J. Biol. Chem. 2009, 284, 6909-6917. [CrossRef] 
62. Laske, C.H.; Teixeira, B.B.M.; Dionello, N.J.L.; Cardoso, F.F. Breeding objectives and economic values for traits of low input family-based beef cattle production system in the State of Rio Grande do Sul. Rev. Bras. De Zootec. 2012, 41, 298-305. [CrossRef]

63. Nosrati, M.; Asadollahpour Nanaei, H.; Amiri Ghanatsaman, Z.; Esmailizadeh, A. Whole genome sequence analysis to detect signatures of positive selection for high fecundity in sheep. Reprod. Domest. Anim. 2019, 54, 358-364. [CrossRef]

64. Safari, E.; Fogarty, N.; Gilmour, A.R.; Atkins, K.; Mortimer, S.; Swan, A.; Brien, F.; Greeff, J.; Van der Werf, J. Genetic correlations among and between wool, growth and reproduction traits in Merino sheep. J. Anim. Breed. 2007, 124, 65-72. [CrossRef] [PubMed]

65. Hanrahan, J.P.; Gregan, S.M.; Mulsant, P.; Mullen, M.; Davis, G.H.; Powell, R.; Galloway, S.M. Mutations in the genes for oocyte-derived growth factors GDF9 and BMP15 are associated with both increased ovulation rate and sterility in Cambridge and Belclare sheep (Ovis aries). Biol. Reprod. 2004, 70, 900-909. [CrossRef] [PubMed]

66. Zhou, S.; Yu, H.; Zhao, X.; Cai, B.; Ding, Q.; Huang, Y.; Li, Y.; Li, Y.; Niu, Y.; Lei, A.J.R. Fertility; Development, Generation of gene-edited sheep with a defined Booroola fecundity gene (FecBB) mutation in bone morphogenetic protein receptor type 1B (BMPR1B) via clustered regularly interspaced short palindromic repeat (CRISPR)/CRISPR-associated (Cas) 9. Repr. Ferti. Dev. 2018, 30, 1616-1621.

67. Abdoli, R.; Mirhoseini, S.; Ghavi Hossein-Zadeh, N.; Zamani, P.; Gondro, C. Genome-wide association study to identify genomic regions affecting prolificacy in Lori-Bakhtiari sheep. Anim. Genet. 2018, 49, 488-491. [CrossRef]

68. Abdurahman, A.; Du, X.; Yao, Y.; Sulaiman, Y.; Aniwashi, J.; Li, Q. Smad4 feedback enhances BMPR1B transcription in ovine granulosa cells. Int. J. Mol. Sci. 2019, 20, 2732. [CrossRef]

69. Shokrollahi, B.; Morammazi, S. Polymorphism of GDF 9 and BMPR 1B genes and their association with litter size in Markhoz goats. Reprod. Domest. Anim. 2018, 53, 971-978. [CrossRef]

70. Christoforou, E.R.; Pitman, J.L. Intrafollicular growth differentiation factor 9: bone morphogenetic 15 ratio determines litter size in mammals. Biol. Reprod. 2019, 100, 1333-1343. [CrossRef]

71. Xu, S.-S.; Gao, L.; Xie, X.-L.; Ren, Y.-L.; Shen, Z.-Q.; Wang, F.; Shen, M.; Eybórsdóttir, E.; Hallsson, J.H.; Kiseleva, T.J. Genome-wide association analyses highlight the potential for different genetic mechanisms for litter size among sheep breeds. Front. Genet. 2018, 9, 118. [CrossRef]

72. Bahire, S.V.; Rajput, P.K.; Kumar, V.; Kumar, D.; Kataria, M.; Kumar, S. Quantitative expression of mRNA encoding BMP/SMAD signaling genes in the ovaries of Booroola carrier and non-carrier GMM sheep. Reprod. Domest. Anim. 2019, 54, 1375-1383. [CrossRef] [PubMed]

73. Zhang, Z.; Liu, Q.; Di, R.; Hu, W.; Wang, X.; He, X.; Ma, L.; Chu, M. Single nucleotide polymorphisms in BMP2 and BMP7 and the association with litter size in Small Tail Han sheep. Anim. Reprod. Sci. 2019, 204, 183-192. [CrossRef] [PubMed]

(C) 2020 by the authors. Licensee MDPI, Basel, Switzerland. This article is an open access article distributed under the terms and conditions of the Creative Commons Attribution (CC BY) license (http://creativecommons.org/licenses/by/4.0/). 